\title{
PENGARUH KEPRIBADIAN DAN EFEKTIVITAS TIM TERHADAP ORGANIZATIONAL CITIZENSHIP BEHAVIOR (OCB) PEGAWAI DI BADAN PENDIDIKAN DAN PELATIHAN KEMENTERIAN DALAM NEGERI
}

\author{
Yarouf Estianda ${ }^{1}$
}

Abstract: The objective of this research is to understand comprehensively the effect of personality and team effectiveness toward Organizational Citizenship Behaviour (OCB) of the civil servant in Education and Training Agency of The Ministry of Home Affairs. The research used a survey method with path analysis applied in testing hyphotesis. It was conducted to 128 civil servants as the respondents which were selected in a simple random way. The data analysis and interpretation reveals that (1) personality has direct positive influence toward $O C B$, (2) team effectiveness has direct positive influence toward $O C B$, (3) personality has direct positive influence toward team effectiveness.

Keywords : Personality, Team Effectiveness, Organizational Citizenship Behaviour (OCB)

\section{PENDAHULUAN}

Salah satu fungsi manajemen SDM adalah training and development. Pelatihan dan pengembangan SDM menjadi suatu keharusan bagi organisasi, karena penempatan pegawai secara langsung dalam pekerjaan tidak menjamin mereka akan berhasil. Pegawai baru sering sering merasa tidak pasti tentang peranan dan tanggung jawab mereka. Dengan adanya pendidikan dan pelatihan maka akan sangat membantu pegawai dalam melaksanakan peran mereka di dalam organisasi.

Perilaku yang menjadi tuntutan organisasi saat ini adalah tidak hanya perilaku in-role, tetapi juga perilaku extra-role. Perilaku extra-role ini disebut juga dengan organizational citizenship behavior (OCB). OCB memiliki banyak bentuk, yaitu sikap siap membantu rekan kerja, melaksanakan pekerjaan dengan sepenuh hati dan bersungguhsungguh, sukarela dalam melaksanakan tugas tambahan dari pekerjaannya, bertanggung jawab atas pekerjaannya, dan berkomitmen untuk terus mengabdi pada organisasi.

Salah satu hal yang menjadi isu pada kompetensi dan kualitas SDM pegawai negeri sipil di Kementerian Dalam Negeri adalah kurangnya rasa tanggung jawab dalam bekerja dan etika baik dalam menjalankan tugas. Mereka juga belum mampu melaksanakan tugas dengan sepenuh hati.

Tentunya dengan kurangnya sikap OCB pada SDM Aparatur pegawai negeri sipil bisa mempengaruhi dedikasi mereka dalam bekerja, guna mewujudkan kualitas yang baik dalam pendidikan dan pelatihan. Oleh karena itu OCB menjadi isu penting

${ }^{1}$ Guru SD Kinderfield Sunter, Jakarta. 
dalam penelitian ini. Konsep penting dalam dunia pendidikan dan pelatihan adalah sikap membantu untuk perkembangan kompetensi SDM. Para SDM Aparatur ini juga harus mampu bekerja dengan sepenuh hati.

Lembaga yang paling bertanggungjawab dalam menghasilkan pelayan publik (PNS) yang mampu bekerja optimal dan memiliki extra role adalah Badan Pendidikan dan Pelatihan Kementerian Dalam Negeri. Disinilah tempat aparatur negara dibina kemampuan profesionalnya, keterampilan serta serta sikap dan etika. Untuk itulah para pegawai Badan Pendidikan dan Pelatihan Kementerian Dalam Negeri menjadi objek dalam penelitian yang diajukan penulis. Para pegawai ini menjadi tumpuan dari berhasil atau tidaknya kegiatan upaya pembinaan aparatur negara.

Berdasarkan pemaparan di atas, maka peneliti menganggap penting untuk meneliti tentang pengaruh kepribadian dan efektivitas tim tehadap organizational citizenship behavior (OCB) pegawai Badan Pendidikan dan Pelatihan Kementrian Dalam Negeri.

\section{Organizational Citizenship Behavior (OCB)}

Pengertian organizational citizenship behavior menurut Robbins dan Coulter (20013:373), "organizational citizenship behavior (OCB) is discretionary behavior that's not part of an employee's formal job requirements, but which promotes the effective functioning of the organization." Organizational citizenship behavior (OCB) adalah sikap sukarela seorang karyawan yang melebihi tugas kerjanya, dimana sikap ini mampu menciptakan efektivitas fungsi dari organisasi. Individu yang memiliki perilaku OCB tidak hanya fokus pada tugas fungsionalnya, namun dia akan berperan melebihi tugas fungsionalnya tanpa mengabaikan tugas utama mereka. Menurut Schermerhorn, et. al., (2010:74), "organizational citizenship are the extras people do to go the extra mile in their work." Organizational Citizenship adalah orang-orang luar biasa yang melakukan pekerjaan melebihi tugas kerja mereka. Masih sejalan dengan konsep OCB menurut Robbins dan Coulter, Schermerhorn berpendapat bahwa individu yang memiliki perilaku OCB bukan berarti bekerja di luar tugas fungsionalnya, namun mereka akan tetap fokus dengan tugas utama mereka, dan bekerja melebihi tugas fungsionalnya. Menurut Newstrom (2011:232), "organizational citizenship behaviors, which are discretionary and helpful actions above and beyond the call of duty that promote the organization's success." Organizational citizenship behavior adalah sikap sukarela dan tindakan membantu yang melampaui panggilan tugas yang menunjang keberhasilan organisasi. Perilaku OCB tidak hanya sekedar sikap baik seorang individu untuk membantu rekan kerjanya, namun juga harus mampu memberikan pengaruh positif bagi organisasi. Terkadang seorang karyawan dapat melupakan tugas fungsionalnya karena terlalu fokus membantu rekan kerjanya. Hellriegel dan Slocum (2011:18) menjelaskan, “organizational citizenship behavior exceeds formal job duties and is often necessary for the organization's survival, including its image and acceptance." Organizational citizenship behavior merupakan sikap untuk mengerjakan tugas melebihi pekerjaan formal dan sering diperlukan untuk keberlangsungan organisasi, termasuk citra dan penerimaan. 
Berdasarkan deskripsi konseptual di atas, maka dapat disintesiskan bahwa organizational citizenship behavior adalah perilaku sukarela seseorang untuk melakukan tugas melebihi fungsinya dalam organisasi yang diperlukan untuk keberlangsungan organisasi dengan indikator yaitu: (1) bekerja sama, (2) sportivitas, (3) membantu orang lain, (4) bekerja melebihi perannya, (5) tanggung jawab sosial.

\section{Kepribadian}

Menurut Gibson, et. al. (2012:107), “an individual's personality is a relatively stable set of characteristics, tendencies, and temperaments that have been significantly formed by inheritance and by social, cultural, and environmental factors." Kepribadian seorang individu adalah seperangkat karakteristik yang relatif stabil, kecenderungan, dan temperamen yang dibentuk oleh warisan dan oleh faktor-faktor sosial secara signifikan, budaya, dan faktor lingkungan. Griffin dan Moorhead (2007:63) mengungkapkan, "personality is the relatively stable set of psychological attributes that distinguish one person from another." Kepribadian adalah himpunan baku atribut psikologis yang membedakan seseorang dari yang lain. Sedangkan menurut Robbins dan Judge (2013:133), "personality is "the dynamic organization within the individual of those psychophysical systems that determine his unique adjustments to his environment." Kepribadian adalah dinamika organisasi antara dalam diri individu dengan sistem-sistem psikofisik yang menentukan penyesuaian yang unik terhadap lingkungannya. Hellriegel dan Slocum (2011:96) juga menjelaskan bahwa kepribadian individu dapat dijelaskan oleh serangkaian faktor yang dikenal sebagai Big Five Personality Factors, "specifically, these personality factors describe an individual's degree of emotional stability, agreeableness, extraversion, conscientiousness, and openness." Secara khusus, faktor kepribadian menggambarkan tingkat stabilitas emosional individu, keramahan, keterbukaan diri, sifat kehati-hatian, dan keterbukaan pada pengalaman.

Berdasarkan deskripsi konseptual di atas, maka dapat disintesiskan bahwa kepribadian adalah kecenderungan dalam diri seseorang untuk menjelaskan karakteristik pola-pola perilakunya yang konsisten dengan indikator yaitu: (1) sikap kehati-hatian, (2) sikap keterbukaan diri, (3) keramahan, (4) kestabilan emosi, (5) keterbukaan terhadap pengalaman. 


\section{Efektivitas Tim}

Untuk mendefinisikan efektivitas tim, West (2012:7) menggunakan lima komponen penting yang dapat menjelaskannya, "team effectiveness can be seen as constituting five main components: (1) task effectiveness is the extent to which the team is successful in achieving its task-related objectives. (2) team member well-being refers to factors such as the well-being or mental health (e.g., stress), growth and development of team members.

(3) team viability is the likelihood that a team will continue to work together and function effectively. (4) team innovation is the extent to which the team develops and implements new and improved processes, products and procedures. (5) Inter-team cooperation is the effectiveness of the team in working with other teams in the organization with which it has to work in order to deliver products or services. Efektivitas tim didefinisikan dengan menggunakan lima komponen utama yang harus ada dalam setiap tim yang efektif. Efektivitas tugas adalah sejauh mana tim ini berhasil mencapai tujuan yang berhubungan dengan tugas organisasi. Kesejahteraan anggota tim, mengacu pada faktor-faktor seperti kesejahteraan atau kesehatan mental (misalnya stres), pertumbuhan dan perkembangan anggota tim. Keberlangsungan tim adalah kemungkinan bahwa tim akan terus bekerja sama dan berfungsi secara efektif. Inovasi tim adalah sejauh mana tim mengembangkan dan menerapkan ide baru dan meningkatkan proses, produk dan prosedur. Kerjasama antar tim adalah efektivitas tim dalam bekerja dengan tim lain dalam organisasi dengan yang harus bekerja dalam rangka untuk memberikan produk atau jasa. Efektivitas tim bisa dipahami sebagai suatu unit yang multidimensi, sesuai yang dijelaskan oleh Weiner et al. (2003:346), "team effectiveness is generally conceived as multifaceted, with an emphasis on both internal (i.e., member satisfaction, team viability) and external (i.e., productivity, performance) criteria." Efektivitas tim umumnya dipahami sebagai suatu multidimensi, dengan penekanan pada baik kriteria internal dan eksternal. Kriteria internal termasuk kepuasan anggota dan keberlangsungan tim. Sedangkan kriteria eksternal termasuk produktivitas dan kinerja. Sedangkan menurut Torrington, Hall dan Taylor (2005:295), "team effectiveness is dependent on the team having agreed goals and methods of working, and a climate where team members can be open and honest and use conflict in a constructive way." Efektivitas tim tergantung pada tujuan yang dimiliki dan disepakati oleh tim tersebut, metode kerja tim, dan iklim di mana anggota tim dapat terbuka dan jujur dan menggunakan konflik dengan cara yang konstruktif.

Berdasarkan deskripsi konseptual di atas, maka dapat disintesiskan bahwa efektivitas tim adalah suatu kondisi dimana sebuah kelompok bisa mencapai tujuan yang telah sepakati, serta mampu memberikan pengaruh terhadap organisasi, anggota kelompoknya, dan keutuhan tim dengan indikator yaitu: (1) kualitas kerja tim, (2) keberlangsungan tim, (3) saling tergantung, (4) dapat diandalkan, (5) kebersamaan tim. 


\section{METODE}

Penelitian ini menggunakan pendekatan kuantitatif, jenis asosiatif kausal dengan metode survey dan analisis jalur (path analysis) sebagai teknik analisis statistiknya. Penelitian ini dilakukan selama tujuh bulan mulai bulan Desember 2013 sampai bulan Juni 2014. Tempat pelaksanaan penelitian di Badan Pendidikan dan Pelatihan Kementerian Dalam Negeri. Populasi berjumlah 187 orang dengan jumlah sampel 128 orang yang dipilih secara acak.

Data dikumpulkan dengan menggunakan instrumen berupa angket yang telah diuji validitas dan reliabilitasnya. Data yang dikumpulkan disajikan dalam statistik deskriptif. Kemudian data dianalisis menggunakan statistik parametris model path analysis, bertujuan untuk menguji pengaruh antar variabel penelitian. Langkah pengujian path analysis sebagai berikut; pengujian normalitas data, perhitungan normalitas galat taksiran dengan uji-Lilifors, perhitungan persamaan regresi, uji signifikansi dan uji linearitas regresi. Selanjutnya dilakukan perhitungan path analysis, untuk menghitung koefisien jalurnya.

\section{HASIL DAN PEMBAHASAN}

\section{Pengaruh Kepribadian terhadap OCB}

Dari hasil pengujian hipotesis pertama dapat disimpulkan bahwa terdapat pengaruh langsung positif kepribadian terhadap OCB. Hasil analisa korelasi sederhana antara kepribadian dengan OCB pegawai diperoleh koefisien korelasi sebesar 0,587 dan nilai koefisien jalur sebesar 0,380. Nilai ini memberikan pengertian bahwa kepribadian berpengaruh terhadap OCB sangat kuat. Hasil tersebut sejalan dengan pernyataan Rothmann and Cooper (2008:28), "personality traits are significant predictors of organizational citizenship behaviour, turnover, absenteeism, safety and leadership effectiveness." Karakteristik kepribadian merupakan prediktor signifikan dari organizational citizenship behaviour, turnover, absensi, keamanan dan efektivitas kepemimpinan. Karakter kepribadian merupakan salah satu faktor yang bisa mempengaruhi OCB. Locke (2009:22) juga menyatakan bahwa salah satu karakteristik kepribadian dalam Big Five Model memiliki pengaruh pada organizational citizenship behavior, "there is considerable evidence that conscientiousness and emotional stability are also related to organizational citizenship behaviors through the broad set of helping behaviors associated with teamwork and customer service." Sifat kehati-hatian dan kestabilan emosi juga terkait dengan perilaku organizational citizenship behavior melalui serangkaian luas perilaku membantu terkait dengan kerja sama tim dan layanan pelanggan. Robbins dan Coulter (20013:373) menjelaskan, "organizational citizenship behavior (OCB) is discretionary behavior that's not part of an employee's formal job requirements, but which promotes the effective functioning of the organization." Organizational citizenship behavior (OCB) adalah sikap sukarela seorang karyawan yang melebihi tugas kerjanya, di mana sikap ini mampu menciptakan efektivitas fungsi dari organisasi. Individu yang memiliki perilaku OCB tidak hanya fokus pada tugas fungsionalnya, namun dia akan berperan melebihi tugas fungsionalnya tanpa mengabaikan tugas utama mereka. Menurut Schermerhorn, et. al., 
(2010:74), "organizational citizenship are the extras people do to go the extra mile in their work." Organizational Citizenship adalah orang-orang luar biasa yang melakukan pekerjaan melebihi tugas kerja mereka. Masih sejalan dengan konsep OCB menurut Robbins dan Coulter, Schermerhorn berpendapat bahwa individu yang memiliki perilaku OCB bukan berarti bekerja di luar tugas fungsionalnya, namun mereka akan tetap fokus dengan tugas utama mereka, dan bekerja melebihi tugas fungsionalnya. Menurut Newstrom (2011:232), "organizational citizenship behaviors, which are discretionary and helpful actions above and beyond the call of duty that promote the organization's success." Organizational citizenship behavior adalah sikap sukarela dan tindakan membantu yang melampaui panggilan tugas yang menunjang keberhasilan organisasi. Dengan demikian hasil penelitian menunjukkan keperibadian yang akurat akan mengakibatkan peningkatan OCB pegawai.

\section{Pengaruh Efektivitas Tim terhadap OCB}

Dari hasil pengujian hipotesis kedua dapat disimpulkan bahwa terdapat pengaruh langsung positif efektivitas tim terhadap OCB. Hasil analisa korelasi sederhana antara efektivitas tim dengan OCB diperoleh koefisien korelasi sebesar 0,566 dan nilai koefisien jalur sebesar 0,320. Nilai ini memberikan pengertian bahwa efektivitas tim berpengaruh terhadap OCB sangat kuat. Hasil tersebut sejalan dengan pendapat Luthans (2011:348), "some aspects of effectiveness may be influenced by how groups form. When they are established, social comparisons and competition exist between members. These may have an impact on the organizational citizenship behaviors exhibited by group members. Beberapa aspek efektivitas mungkin dipengaruhi oleh bagaimana kelompok terbentuk. Ketika mereka ditetapkan, perbandingan sosial dan kompetisi di antara anggota. Hal ini berdampak pada organizational citizenship behaviors.

Karakter dari efektivitas tim adalah dapat diandalkan, adanya hubungan ketergantungan antar anggota tim, dan memiliki target dan tujuan yang telah disepati dari organisasi. West (2012:7) menggunakan lima komponen penting yang dapat menjelaskan efektivitas tim, yaitu, "team effectiveness can be seen as constituting five main components: (1) task effectiveness is the extent to which the team is successful in achieving its task-related objectives. (2) team member well-being refers to factors such as the well-being or mental health (e.g., stress), growth and development of team members. (3) team viability is the likelihood that a team will continue to work together and function effectively. (4) team innovation is the extent to which the team develops and implements new and improved processes, products and procedures. (5) Inter-team cooperation is the effectiveness of the team in working with other teams in the organization with which it has to work in order to deliver products or services. Efektivitas tim didefinisikan dengan menggunakan lima komponen utama yang harus ada dalam setiap tim yang efektif. Efektivitas tugas adalah sejauh mana tim ini berhasil mencapai tujuan yang berhubungan dengan tugas organisasi. Kesejahteraan anggota tim, mengacu pada faktor-faktor seperti kesejahteraan atau kesehatan mental (misalnya stres), pertumbuhan dan perkembangan anggota tim. Keberlangsungan tim adalah kemungkinan bahwa tim akan terus bekerja sama dan berfungsi secara efektif. Inovasi tim adalah sejauh mana tim mengembangkan dan menerapkan ide baru dan 
meningkatkan proses, produk dan prosedur. Kerjasama antar tim adalah efektivitas tim dalam bekerja dengan tim lain dalam organisasi dengan yang harus bekerja dalam rangka untuk memberikan produk atau jasa. Efektivitas tim bisa dipahami sebagai suatu unit yang multidimensi, sesuai yang dijelaskan oleh Weiner et al. (2003:346), "team effectiveness is generally conceived as multifaceted, with an emphasis on both internal (i.e., member satisfaction, team viability) and external (i.e., productivity, performance) criteria." Efektivitas tim umumnya dipahami sebagai suatu multidimensi, dengan penekanan pada baik kriteria internal dan eksternal. Kriteria internal termasuk kepuasan anggota dan keberlangsungan tim. Sedangkan kriteria eksternal termasuk produktivitas dan kinerja. Secara langsung indikator dari efektivitas tim dapat memberikan kepastian untuk memprediksi perilaku OCB pada individu pegawai.

\section{Pengaruh Kepribadian terhadap Efektivitas Tim}

Dari hasil pengujian hipotesis ketiga dapat disimpulkan bahwa terdapat pengaruh langsung positif kepribadian terhadap efektivitas tim. Hasil analisa korelasi sederhana antara kepribadian dengan efektivitas tim diperoleh koefisien korelasi sebesar 0,649 dan nilai koefisien jalur sebesar 0,649. Nilai ini memberikan pengertian bahwa kepribadian berpengaruh terhadap efektivitas tim sangat kuat.Hasil tersebut sejalan dengan pernyataan Weiner et. al. (2003:339), "personality composition influences. . . it is clear that personality composition has important implications for team effectiveness". Komposisi karakter kepribadian yang mempengaruhi kinerja tim, dengan pasti kepribadian memiliki implikasi penting untuk efektivitas tim.

Sebuah tim akan efektif jika memiliki keberagaman kepribadian dari anggota timnya. Griffin dan Moorhead (2007:63) mengungkapkan, "personality is the relatively stable set of psychological attributes that distinguish one person from another." Kepribadian adalah himpunan baku atribut psikologis yang membedakan seseorang dari yang lain. Sedangkan menurut Robbins dan Judge (2013:133), "personality is "the dynamic organization within the individual of those psychophysical systems that determine his unique adjustments to his environment." Kepribadian adalah dinamika organisasi antara dalam diri individu dengan sistem-sistem psikofisik yang menentukan penyesuaian yang unik terhadap lingkungannya. Hellriegel dan Slocum (2011:96) juga menjelaskan bahwa kepribadian individu dapat dijelaskan oleh serangkaian faktor yang dikenal sebagai Big Five Personality Factors, "specifically, these personality factors describe an individual's degree of emotional stability, agreeableness, extraversion, conscientiousness, and openness." Secara khusus, faktor kepribadian menggambarkan tingkat stabilitas emosional individu, keramahan, keterbukaan diri, sifat kehati-hatian, dan keterbukaan pada pengalaman.

Tim akan efektif jika dibentuk oleh karakter kepribadian yang lengkap yaitu anggota tim yang memiliki sikap kehati-hatian, keramahan, keterbukaan diri, kestabilan emosi, dan keterbukaan terhadap pengalaman. Tim yang seperti ini akan memiliki kualitas kerja tinggi, kebersamaan yang kuat, dan keberlangsungan tim yang lama. 


\section{PENUTUP}

Kesimpulan: Pertama, terdapat pengaruh langsung positif kepribadian terhadap OCB. Hal ini berarti kepribadian yang akurat akan mengakibatkan peningkatan OCB pegawai Badan Pendidikan dan Pelatihan Kementerian Dalam Negeri. Kedua, terdapat pengaruh langsung positif efektivitas tim terhadap OCB. Hal ini berarti peningkatan efektivitas tim akan mengakibatkan peningkatan OCB pegawai Badan Pendidikan dan Pelatihan Kementerian Dalam Negeri. Ketiga, terdapat pengaruh langsung positif kepribadian terhadap efektivitas tim. Hal ini berarti kepribadian yang akurat akan mengakibatkan peningkatan efektivitas tim pegawai Badan Pendidikan dan Pelatihan Kementerian Dalam Negeri.

Saran: (1) Bagi pegawai Badan Pendidikan dan Pelatihan Kementerian Dalam Negeri agar dalam melaksanakan tugas harus terbuka dalam menerima saran dari rekan kerja, ramah dalam melayani, menjaga sikap pada saat bertugas, berhati-hati dalam menyikapi kondisi saat bekerja serta harus senantiasa terbuka dengan pengalaman baru. (2) Bagi Kepala Badan Pendidikan dan Pelatihan Kementerian Dalam Negeri selaku pimpinan harus dapat memberikan dorongan dan pengutan positif tentang visi organisasi, hal ini mampu membentuk pribadi pegawai menjadi lebih positif dalam melaksanakan pekerjaannya serta menyelesaikan tugas dengan optimal. (3) Bagi Badan Pendidikan dan Pelatihan Kementerian Dalam Negeri hendaknya menyediakan program kerja dengan konten yang dipenuhi berbagai macam pelatihan inovatif baik berbentuk loka karya atau seminar, serta berbagai studi banding dengan benar-benar melakukan upaya benchmark dalam usaha pengembangan kepribadian positif dan kebersamaan antara anggota organisasi.

\section{DAFTAR RUJUKAN}

Champoux, Joseph E., Organizational Behavior: Integrating Individuals, Groups, and Organizations, $4^{\text {th }}$ Edition. New York: Routledge, 2011.

George, Jennifer M., Gareth Jones, Understanding and Managing Organizational Behavior, $6^{\text {th }}$ Edition. New Jersey: Pearson Education, Inc., 2012.

Gibson, James L., et.al, Organizations: Behavior, Structure, Processes. New York: The McGraw-Hill Companies, Inc., 2012.

Griffin, Ricky W. dan Gregory Moorhead, Organizational Behavior, Managing People and Organizations, $8^{\text {th }}$ Edition. Boston: Houghton Mifflin, 2007.

Hellriegel, Don dan John W. Slocum, Jr, Organizational Behavior, $13^{\text {th }}$ Edition. Mason: South-Western Cengage Learning 2011.

Jex, Steve M., Organizational Psychology: a Scientist-Practitioner Approach. New York: John Wiley \& Sons, Inc., 2002. 
Kadir. Statistika untuk Penelitian Ilmu-ilmu Sosial. Jakarta: Rosemata, 2010.

Locke, Edwin A., Handbook Of Principles Of Organizational Behavior, 2nd Edition. West Sussex: John Wiley \& Sons, Ltd, 2009.

Luthans, Fred, Organizational Behavior: an Evidence-Based Approach, 12 th Edition. New York: McGraw-Hill/Irwin, 2011.

Mc Shane, Steven L. dan Mary Ann Von Glinow, Organizational Behavior: Emerging Knowledge and Practice for the Real World, $4^{\text {th }}$ Edition. New York: McGrawHill/Irwin, 2008.

Millward, Lynne, Understanding Occupational and Organizational Psychology. London: Sage Publication, 2005.

Newstrom, John W, Organizational Behavior: Human Behavior at Work, 13 th Edition. New York: McGraw-Hill Education, 2011.

Robbins, Stephen P. dan Mary Coulter, Management, 11 th Edition. New Jersey: Pearson Education, Inc., 2012.

Robbins, Stephen P. dan Timothy A. Judge, Organizational Behavior, 11 th Edition. New Jersey: Pearson Education, Inc., 2013.

Rothmann, Ian and Cary Cooper, Organizational and Work Psychology. London: Hodder Education, 2008.

Schermerhorn, John R., Jr, et. al., Organizational Behavior, 11 th Edition. Danvers: John Wiley \& Sons, Inc, 2010. 
Schneider, Benjamin dan D. Brent Smith, Personality and Organizations. Mahwah: Lawrence Erlbaum Associates, Inc., 2004.

Torrington, Derek, Laura Hall and Stephen Taylor, Human Resource Management, $6^{\text {th }}$ Edition. Harlow: Pearson Education Limited, 2005.

Wagner, John A., Organizational Behavior: Securing Competitive Advantage, $5^{\text {th }}$ Edition. New York: Routledge, 2010.

Weiner, Irving B.. et. al, Volume 12 Industrial And Organizational Psychology. New Jersey: John Wiley \& Sons, Inc, 2003.

West, Michael A., Effective Teamwork: Practical Lessons from Organizational Research, $3^{\text {rd }}$ Edition. West Sussex: John Wiley \& Sons, Ltd, 2012. 